\title{
A review of feeding intolerance in critically ill children
}

\author{
Lyvonne N. Tume ${ }^{1,2}$ (D) Frédéric V. Valla ${ }^{3}$
}

Received: 5 June 2018 /Revised: 9 August 2018 / Accepted: 10 August 2018 / Published online: 17 August 2018

(C) The Author(s) 2018

\begin{abstract}
Ensuring optimal nutrition is vital in critically ill children and enteral feeding is the main route of delivery in intensive care. Feeding intolerance is the most commonly cited reason amongst pediatric intensive care unit healthcare professionals for stopping or withholding enteral nutrition, yet the definition for this remains inconsistent, nebulous, and entirely arbitrary. Not only does this pose problems clinically, but research in this field frequently uses feeding intolerance as an endpoint and the heterogeneity in this definition makes the comparison of studies difficult and meta-analysis impossible. We reviewed the use of, and definitions of, the term feed intolerance in pediatric intensive care research papers in the last 20 years. Gastric residual volume remains the most common factor used to define feed intolerance, despite the lack of evidence for this. Healthcare professionals would benefit from further education to improve their awareness of the limitations of the markers to define feeding intolerance, and the international PICU community needs to agree a consistent definition of this phenomenon to improve consistency in both practice and research.

Conclusion: This paper will provide a narrative review of the definitions of, evidence for, and markers of feeding intolerance in critically ill children.

What is Known?:

- Feeding intolerance is a commonly cited reason amongst pediatric intensive care unit healthcare professionals for stopping or withholding enteral nutrition.

- There is no agreed definition for feeding intolerance in critically ill children.

What is New?:

- This paper provides an up to date review of the definitions of, evidence for, and markers of feeding intolerance in critically ill children.

- Despite no evidence, gastric residual volume continues to drive clinical bedside decisions about enteral feeding and feeding tolerance.
\end{abstract}

Keywords Pediatric $\cdot$ Intensive care $\cdot$ Nutrition $\cdot$ Infant

\section{Abbreviations}

ASPEN American Society of Parenteral and Enteral Nutrition

Communicated by Mario Bianchetti

Lyvonne N. Tume

Lyvonne.Tume@UWE.ac.uk

Frédéric V. Valla

Frederic.valla@chu-lyon.fr

1 Faculty of Health and Applied Sciences, The University of the West of England, Glenside Campus, Blackberry Hill, Stapleton, Bristol BS16 1DD, UK

2 Pediatric Intensive Care Unit, Bristol Children's Hospital, Upper Maudlin Street, Bristol, UK

3 Pediatric Intensive Care Unit, Hôpital Femme Mère Enfant, Hospices Civils de Lyon, 59 Bd Pinel, 69500 Lyon-Bron, France
ESPGHAN European Society for Pediatric Gastroenterology, Heptatology and Nutrition

EN Enteral nutrition

GI Gastrointestinal

GRV Gastric residual volume

ICU Intensive care unit

NEC Necrotising enterocolitis

PICU Pediatric intensive care unit

PN Parenteral nutrition

\section{Introduction}

Recent studies reveal that feeding intolerance is one of the main reasons that enteral nutrition is withheld in the pediatric intensive care unit (PICU) [16, 40, 43, 44]. However, the concept of feeding intolerance in critically 
ill children has never been universally defined or agreed, thus is subjective, lacks evidence, and is inconsistent internationally [46]. This nebulous and inconsistent definition of feeding intolerance is not helpful for clinical practice or for research. Every PICU clinician (nurse, doctor, or dietician) uses the term feeding intolerance but their definitions are different across different PICUs (and sometimes even across the same PICU). It is likely that this inconsistent definition, which lacks an evidence base, is conservative and likely directs the withholding of enteral nutrition at a much lower threshold than is necessary. This is problematic because we know that critically ill children rarely receive even half of the energy requirements they are predicted to require [25] and that optimal energy delivery is essential to meet the demands of critical illness. Furthermore, there is increasing evidence to show that inadequate nutrition can prolong the length of mechanical ventilation, intensive care stay, and worsen patient's clinical outcomes [15, 49]. Conversely, a more relaxed definition of feeding intolerance could also potentially lead to unsafe feeding practices. The latest ASPEN guidance [26] acknowledges feeding intolerance as a common barrier and only suggests the use of protocols that guide the detection and management of EN intolerance should be used; however, no guidance on how best to do this is made. The ESPGHAN nutrition committee 2010 position statement on practical approach of enteral nutrition in children (outside the PICU) highlighted diarrhea, nausea, vomiting, and regurgitations or aspirations as the major signs of enteral nutrition complications in children [4]. They specify the importance of monitoring for these signs, even though they may have other causes, not always involving enteral nutrition. The extrapolation of this guidance to critically ill children is questionable; therefore, it is timely to review the literature and evidence around this topic.

The online medical dictionary (Medicine.Net) defines food intolerance as "difficulty in digesting a food" [23]. If applied to the pediatric intensive care unit, this implies the nonabsorption of enteral feed, delivered to the child, usually via the gastric route (via a feeding tube). This includes gastric and gut motility issues, and/or malabsorption issues, and/or abdominal complications. The variable interpretation of this by clinicians in clinical practice remains problematic. In addition to what is considered as feeding intolerance (indicated by the child's response to enteral feeds), there can be a fear of feeding intolerance by clinicians, whereby feeds are not commenced or withheld in anticipation in particular conditions or with the use of specific PICU therapies. Both inevitably lead to the same outcome, the withholding of enteral nutrition. This paper will review the definitions of, evidence for, and markers of feeding intolerance in critically ill children. Parenteral nutrition $(\mathrm{PN})$ aspects are out the scope of this review.

\section{Methods}

A narrative review was undertaken. The databases CINAHL plus, EBSCOhost, and Medline were searched in January 2018 using the term/s "feeding intolerance" and "tolerance" and "child" or "pediatric." We also replicated the search strategy of the systematic review of feeding intolerance in adult intensive care [2]. Inclusion criteria were papers published in English or French and related to critically ill children (aged term to 17 years) without a limit applied to search years. However, as only one review paper specifically discussed feeding intolerance [46], we broadened our search to any study in critically ill children where feeding intolerance was defined. For this, we searched the PICU trials registry PICUTrials.net [29] and searched for common nutritional interventions where feeding intolerance may have been used as an outcome. Pediatric papers which were discussion or review papers are referred to, where relevant. This paper will discuss the pediatric evidence for feeding intolerance and review the definitions used.

\section{Results}

We found 15 pediatric research papers in total in which the term feeding intolerance or feed intolerance was defined $[5,7$, $9,10,19-22,28,33-35,37,45,48,50]$. These were a mixture of randomized trials, prospective and retrospective observational cohort studies, surveys, and before and after studies. We did not formally appraise the quality of these papers, as our aim was to describe the definition and use of the term feeding intolerance. A further 32 papers were review or discussion papers $[n=6][2,6,13,18,46,47]$, surveys $[n=5][16,40$, $41,43,44]$, research papers which support this review but are not included in papers which defined feeding intolerance $[n=$ 19] [3, 8, 11, 12, 14, 15, 17, 24, 25, 27, 30-32, 36, 38, 39, 42, 49], and guidelines $[n=2][4,26]$ where feeding intolerance was mentioned or discussed.

\section{The pathophysiology of feeding intolerance in critically ill children}

Enteral feeding is delivered either through the gastric route (into the stomach) or into the intestine in the critically ill child. During critical illness, the child (aged $0-17$ years) has to adapt and respond to both the disease process causing the critical illness (and does this in a physiological age-dependant manner) and the medications and therapies applied to the child in the intensive care unit. Gastric dysmotility, a problem in the critically ill child, is defined by Martinez et al. as "the functional capacity of the stomach to move the contents forward by abnormally slow and/or uncoordinated activity of the gastric or antroduodenal musculature" [20]. This results in the 
phenomena of delayed gastric emptying which is estimated to occur in around half of critically ill children [21]. The causes for delayed gastric emptying are multifactorial; alterations in hormonal responses (increased levels of ghrelin, motilin, cholecystokinin, glucagon-like-peptide-1, peptide-YY, amylin) and alterations of vagal tonus, vasoactive intestinal peptide, and nitric oxide secretion are combined with the side effects of opiates, sedatives, neuromuscular blocking agents, and catecholamines alter GI motility and slow transit time, usually in a dose-dependent manner [20]. As a result, stomach motor discoordination, antroduodenal discoordination, and gut contraction/relaxation discoordination will occur. An altered gastrointestinal motility, which is multifactorial, is the primary mechanism underlying many of the signs and symptoms of feeding intolerance in the critically ill children such as large gastric residual volumes, constipation, and abdominal distention [18]. Other mechanisms include gut tissue alteration, due to gut inflammation or hypoperfusion, which are responsible for malabsorption and bowel movement alterations. Furthermore, pressure changes induced by positive pressure ventilation may affect the renin-angiotensin system and consequently reduce splanchnic perfusion. Many children admitted to the PICU also have a degree of circulatory shock, and this has a direct effect on reducing gut perfusion as may direct compression, either from trauma or from abdominal compartment syndrome. The critically ill child is also lying (usually supine) and immobile, a non-physiological state. Administering enteral nutrition may then place additional oxygen demands on the gut, which can result in ischemia with negative consequences $[18,20]$.

\section{Definitions of feeding intolerance in critically ill patients found in the literature search}

Surveys of PICU healthcare professionals (nurses, physicians, and dieticians) reveal a number of commonly used signs and symptoms to define feeding intolerance [16, 40, 43, 44]. These include gastric residual volumes (GRV), vomiting, diarrhea, abdominal distention and pain/discomfort, and the use of serum lactate $[41,46]$. However, evidence to support each of these as an indicator of feeding intolerance is weak or absent, and in critically ill children, a multitude of non-feedrelated factors can produce these signs and symptoms. Nutrition research in critically ill children also frequently uses "feeding intolerance" as an outcome measure and a plethora of different definitions has been used to define this $[5,7,9,10$, 19-22, 28, 33-35, 37, 45, 48, 50] [Table 1]. In pediatrics, these include the use of gastric residual volume alone, possibly including a change in the aspirate colour or in combination with abdominal signs and symptoms. Most [87\%, 13/15] studies used GRV either as the main parameter to determine feeding intolerance or in combination with other parameters in $54 \%(8 / 15)$ (Table 1). The GRV critical threshold used varied markedly from a threshold of $2 \mathrm{ml} / \mathrm{kg}$ body weight to more than $50 \%$ of the volume of the feed given over the previous $4 \mathrm{~h}$ [Table 1]. Two studies defined feeding intolerance as the number of stools per $24 \mathrm{~h}$ period and/or the presence of vomiting or abdominal pain and/or tenderness [10, 19]. Similarly, an adult systematic review of 72 intensive care studies [2] found that 43 different definitions of feeding intolerance were used, with GRV used in $88 \%$ of these alone or in combination with other signs.

\section{Signs and symptoms used to define feeding intolerance in critically ill children}

First, signs of feeding tolerance/intolerance (i.e., feeding intolerance markers) have to be distinguished from signs or conditions that imply that the patient is not ready to be fed (i.e., feeding intolerance predictors). Feeding intolerance predictors, encountered prior to feed infusion, are a presumption that feeds will not be tolerated. They relate to various anatomical and pathophysiological conditions that need to be treated prior to feeding initiation. Conversely, feeding intolerance markers are signs/symptoms observed during EN administration, presumed to be indicative of feeding intolerance. Healthcare professionals then have to establish their causality, distinguishing feeding issues and non-feed-related causes, in order to manage them appropriately to ensure future feeding tolerance. Markers and predictors include increased gastric residual volume, upper gastrointestinal (GI) signs and symptoms, bowel sounds and frequency of bowel movements, and lastly abdominal pain and/or distention. Each of these will now be discussed.

\section{Gastric residual volume}

Gastric residual volume used as a surrogate marker of gastric emptying is used extensively in a majority of intensive care units (neonatal, pediatric, and adult) [6, 13, 40, 44, 46]. However, the evidence for it as a valid marker of gastric emptying is not supported [21]. An increased GRV can occur in up to $50 \%$ critically ill children $[21,46]$. GRV comprises both the enteral feed administered, in addition to gastric secretions produced, and many clinicians fail to consider the large impact of the latter on this volume. Furthermore, there is an inaccurate assumption that the relationship between feed volume infused and GRV is linear [46]. However, a prospective study in critically ill children showed higher GRVs did not correlate with delayed gastric emptying [21]. The volume of GRV obtained is known to be affected by multiple factors: patient position, feeding tube tip position and diameter of feeding tube being aspirated, the type of tube (rigid aspiration tube or soft silicone or polyurethane nutrition tube), the syringe size used to aspirate, the nurses' technique in aspiration, and the type of feeding delivery method used (bolus versus continuous) [1, 46]. If 
Table 1 Definition of feed intolerance used in studies in critically ill children

\begin{tabular}{|c|c|c|c|}
\hline Study & Study type & Objective of study & Definition of feed intolerance \\
\hline Mayer et al. 2002 [22] & $\begin{array}{l}\text { Prospective } \\
\quad \text { interventional study }\end{array}$ & $\begin{array}{l}\text { Amylin associated with delayed } \\
\text { gastric emptying in children }\end{array}$ & GRV $>125 \% 4 \mathrm{~h}$ following a feed challenge \\
\hline Lyons et al. 2002 [19] & $\mathrm{RCT}$ & $\begin{array}{l}\text { Continuing vs withholding transpyloric } \\
\text { feeding during weaning and } \\
\text { extubation }\end{array}$ & Abdominal distention and pain or tenderness \\
\hline $\begin{array}{l}\text { Horn and } \\
\quad \text { Chamboyer } 2003 \text { [10] }\end{array}$ & RCT & $\begin{array}{l}\text { Continuous versus intermittent } \\
\text { bolus feeding }\end{array}$ & $\begin{array}{l}\text { No. of stools per } 24 \mathrm{~h} \text { and prevalence of diarrhea } \\
\text { and vomiting }\end{array}$ \\
\hline Sanchez et al. 2007 [33] & Prospective observational & $\begin{array}{l}\text { The tolerance of early transpyloric } \\
\text { feeding in critically ill children }\end{array}$ & $\begin{array}{l}\text { Significant abdominal distention with clinical } \\
\text { alteration or increase in intra-abdominal } \\
\text { pressure, GRV }>50 \% \text { of the volume } \\
\text { administered in the previous } 4 \text { h, severe } \\
\text { diarrhea ( }>5 \text { loose stools a day) or severe NEC }\end{array}$ \\
\hline Sanchez et al. 2007 [34] & Prospective observational & $\begin{array}{l}\text { The tolerance of early transpyloric } \\
\text { feeding in critically ill children } \\
\text { after heart surgery }\end{array}$ & $\begin{array}{l}\text { GRV }>50 \% \text { of the volume administered in the } \\
\text { previous } 4 \mathrm{~h}\end{array}$ \\
\hline Willis et al. 2008 [48] & Prospective observational & $\begin{array}{l}\text { The safety of feeding neonates } \\
\text { on prostaglandin }\end{array}$ & $\begin{array}{l}\text { GRV }>2 / 3 \text { of prior feed or bilious vomiting or an } \\
\text { increase in abdominal girth of }>3 \mathrm{~cm} \text { over an } 8 \mathrm{~h} \\
\text { period or occult blood in stools or x-ray } \\
\text { indicating signs of NEC }\end{array}$ \\
\hline $\begin{array}{r}\text { Van Waardenburg } \\
\text { et al. } 2009 \text { [45] }\end{array}$ & $\mathrm{RCT}$ & $\begin{array}{l}\text { Early protein and energy in } \\
\text { critically ill children }\end{array}$ & $\begin{array}{l}\text { GRV }>50 \% \text { of the administered feed volume over } \\
\text { the previous } 4 \mathrm{~h} \text { on more than one occasion, } \\
\text { occurrence of any gastric distention and } \\
\text { vomiting and/or diarrhea defined as }>4 \text { stools } \\
\text { per day of watery consistency and leading to } \\
\text { substantial fluid loss as negative fluid balance or } \\
\text { by hemodynamic consequences }\end{array}$ \\
\hline $\begin{array}{l}\text { Simackachorn } \\
\text { et al. } 2011 \text { [35] }\end{array}$ & $\mathrm{RCT}$ & $\begin{array}{l}\text { Effect of EN supplemented with } \\
\text { pre- and probiotics on fecal } \\
\text { microflora }\end{array}$ & $\begin{array}{l}\text { Abdominal distention, episodes of vomiting and } \\
\text { diarrhea and GRV (> 50\% of the previously } \\
\text { administered volume) }\end{array}$ \\
\hline $\begin{array}{l}\text { Brown et al. } \\
2012[5]\end{array}$ & Before and after study & To test the impact of a feeding protocol & $\begin{array}{l}\text { Emesis, elevated GRV } \times 2 \text {, or elevated GRV } \times 1 \\
\text { and abdominal girth increase }\end{array}$ \\
\hline Panchal et al. 2014 [28] & $\begin{array}{l}\text { Retrospective } \\
\text { observational }\end{array}$ & $\begin{array}{l}\text { Transpyloric feeding in shocked } \\
\text { children }\end{array}$ & $\begin{array}{l}\text { Used a preterm definition: GRV }>2 \mathrm{ml} / \mathrm{kg} \text { or } 1 / 2 \\
\text { the amount fed over the prior } 3 \mathrm{~h} \text {, a change in } \\
\text { the color of the aspirate top green or red, abdomi- } \\
\text { nal } \\
\text { distention with tenderness or a change in stool } \\
\text { consistency to brown or red }\end{array}$ \\
\hline Hamilton et al. 2014 [9] & Before and after study & Testing of a new feeding protocol & $\begin{array}{l}\text { GRV }>3 \mathrm{ml} / \mathrm{kg} \text { or evidence of EN intolerance after } \\
4 \mathrm{~h} \text { of feeding }\end{array}$ \\
\hline $\begin{array}{l}\text { Yoshimuru et al. } 2015 \\
{[50]}\end{array}$ & Before and after study & Testing of a new feeding protocol & $\begin{array}{l}\text { GRV > half of the quartering dose after } 2 \mathrm{~h} \text { of feed } \\
\text { delivery }\end{array}$ \\
\hline $\begin{array}{l}\text { Somnez-Duzkaya } \\
\text { et al. } 2016[37]\end{array}$ & $\mathrm{RCT}$ & $\begin{array}{l}\text { Continuous post pyloric vs } \\
\text { intermittent gastric feeding } \\
\text { on VAP }\end{array}$ & $\begin{array}{l}\text { GRV greater than } 2 / 3 \text { of the last feed in intermittent } \\
\text { gastric bolus feeding }\end{array}$ \\
\hline Fayazi et al. 2016 [7] & $\mathrm{RCT}$ & Continuous versus intermittent feeding & $\begin{array}{l}\text { GRV }>100 \mathrm{ml} \text { after } 4 \mathrm{~h} \text { of feeding by either } \\
\text { method }\end{array}$ \\
\hline Martinez et al. 2017 [21] & Prospective observational & $\begin{array}{l}\text { To assess delayed GE in critically } \\
\text { ill children }>12 \text { months of age }\end{array}$ & $\begin{array}{l}\mathrm{GRV}>3 \mathrm{ml} / \mathrm{kg} \text { or }>150 \mathrm{ml} \text { or if one of the } \\
\text { following were recorded in a } 24 \text {-h period: } 2 \text { or } \\
\text { more episodes of emesis, bilious or non-bilious; } \\
3 \text { or more episodes of loose stool; abdominal } \\
\text { distention defined as } 2 \text { or more increases in } \\
\text { abdominal girth or subjective abdominal } \\
\text { discomfort }\end{array}$ \\
\hline
\end{tabular}

aspirate is obtained, there is a belief that this volume is entirely accurate and decisions are made based on this volume, with no evidence to underpin any GRV threshold level to indicate “intolerance.” Clinicians' fears around increased GRV relate to the perceived risk of vomiting and pulmonary aspiration with increased GRV, but this is not supported in children or 
adults [27, 30, 42]. For children, an arbitrary cutoff volume is not useful given the wide weight and age variations. If a GRV threshold had to be set to define intolerance, this should rather be set in milliliter per kilogram or milliliter per body surface area but should also account for volumes administered. However, no research has ever shown that a critical amount is significant, or predicts a greater risk of aspiration.

\section{Vomiting}

Vomiting in critically ill children can occur in up to $31 \%$ patients [18] and is perceived to be dangerous due to its risk of aspiration and pneumonia. When the vomit contains the administered feed, it is considered a feeding intolerance sign. However, the cause of vomiting may not be related to enteral feeding. Indeed, the amount or type of feed is not necessarily responsible for any upper GI signs and symptoms, and as a consequence, treating the cause may be more appropriate than withholding feeds. Gastroesophageal reflux and vomiting may reflect bowel obstruction or paralytic ileus, but can also be induced by a number of other factors. Vomiting in the critically ill child may also be caused by the wakening child and irritation of the endotracheal tube, by oral and endotracheal suctioning and coughing with secretions as well as by incorrect gastric tube position or inadequate gastric decompression. In infants, gastroesophageal reflux is common due to the immaturity of the lower esophageal sphincter. Furthermore, a number of common PICU medications (opiates, sedatives, catecholamines) or less common (chemotherapeutic agents) can cause nausea and vomiting. Iatrogenic withdrawal syndrome, which is also frequent in the pediatric setting, can also result in both vomiting and diarrhea [11]. Supine positioning may also increase the likelihood of regurgitation and vomiting in the critically ill population. Vomiting, can, however be prevented using antiemetic medications, adapting feed delivery (continuous feeding or post pyloric feeding) before withholding feeds.

\section{Bowel sounds and the frequency of bowel movements}

The presence and frequency of bowel sounds may be a helpful indicator of bowel function and may indicate paralytic ileus or bowel obstruction. However, these can be difficult to assess with certain therapies (such as high-frequency oscillatory ventilation). Additionally, the correlation between bowel sounds and delayed gastric emptying in the ICU is poor [38]. In the past decade, early rehabilitation after surgery concepts in children has become well established; these include early postoperative feeding $[31,32]$ and they found return of bowel sounds was a poor marker of gut motility. Recommended practice is therefore that bowel sounds should not be used to decide whether to initiate or withhold feeding. There is a clear relationship between enteral nutrition (EN) and bowel movements in the critically ill. Patients require some enteral input to generate any bowel movements. If this is delayed or only delivered in small amounts, stool output will consequently be affected. Surprisingly, constipation, which is frequent in critically ill children, is less commonly considered as a sign of feeding intolerance in PICU. A study of 150 children [17] found constipation occurred in $47 \%$ of children who spent more than 3 days in the PICU. A number of factors influenced the development of constipation (defined as 3 days without a bowel movement) including immobility, opiates and other commonly used PICU drugs, delayed enteral feed administration, splanchnic hypoperfusion, inflammation, sepsis, and electrolyte disturbances (most notably hypercalcemia, hypokalemia, hypomagnesemia, and hypophosphatemia). They found a significantly higher incidence in surgical patients and in older higher weight children, in addition to those who received little enteral nutrition which was started later [17]. Diarrhea (still inadequately defined in neonates and small infants) can also occur in critically ill children, although the reported incidence is lower than that reported in critically ill adults of $15-38 \%[36,47]$. Diarrhea is commonly defined in adults as more than three to five liquid stools per day [36], but in infants, it is normal to pass a semi-liquid stool after each feed, making the definition more difficult. The Bristol stool chart is validated in adults and older children [14], but no validated tool is available in infants and toddlers. Diarrhea can be caused by various non-feed-related factors such as infections (Clostridium difficile) or other microbiomeacquired imbalance due to gut failure, antibiotic use, or fasting/feeding regimen changes and shock states and hypoalbunemia $[36,47]$. In addition, formula type and the osmolality of feed administered and delivery method (continuous versus bolus) can also produce diarrhea and impact on this [36]. Finally, the first stool in critically ill children is loose most of the time [36], with no link to type or amounts of feeds. This may be more likely to be related to gut inflammation, constipation, and gut microbiome alteration. In other words, both constipation and diarrhea are multifactorial and commonly non-feed related, in the PICU setting.

\section{Abdominal pain and/or distention}

Abdominal distention is another subjective sign that may indicate feed intolerance [3] resulting from altered gut motility, but its specificity and sensitivity are once again limited. It can be mimicked or concealed by generalized edema, ascites, a full bladder, peritoneal dialysis, and swallowing air with hand ventilation or non-invasive ventilation, if there is inadequate gastric decompression. Nevertheless, abdominal girth can be objectively measured and assessed [39], although there is no validated threshold of distention that is significant (in absolute 
value or percentage). Like many other PICU assessment parameters, the absolute value (abdominal girth if measured in a consistent way and place) can be used as a trend over time. Intra-abdominal pressure, estimated by urinary bladder pressure monitoring through the urinary catheter [39], is not a sign of feeding intolerance but rather a sign of "risk to feed" if elevated. Indeed, high intraabdominal pressure is the consequence of severe ascites or intra-abdominal compression. Abdominal pain or discomfort is not only very subjective, but in many critically ill children difficult to assess, and caused by a number of factors including trauma, surgery, wounds, trapped gas, constipation, gut dysmotility, medications, lines, and surgical drains, with no link to feeding tolerance potentially. In children who can self-report, it is an important sign, but it is problematic for many critically ill children.

\section{Markers of systematic tissue perfusion}

Reduced splanchnic perfusion can alter the tolerance to EN and has been reported to induce both functional and structural changes in the GI tract [20]. EN increases oxygen and metabolic demands of the gut, which may lead to oxygen supply and delivery imbalances if the gut is underperfused. Vasoactive drugs may worsen this inadequate intestinal perfusion further. Serum lactate is a commonly used factor to determine inadequate tissue perfusion [43], but other methods of tissue perfusion assessment, such as splanchnic near-infrared spectroscopy, are possible, though used rarely [12, 43]. However, due to fears around suboptimal tissue perfusion, serum lactate in particular is frequently used as an indicator to delay or withhold enteral feeding. Although increased lactate indicates inadequate tissue perfusion, using it as a maker to stop or withhold feeds is problematic and subjective, as variable lactate thresholds are used [43]. In the PICU context, lactate is likely to be used as a feeding intolerance predictor, rather than a feeding intolerance sign. No research has examined the use of splanchnic NIRS in relation to enteral feeding tolerance in critically ill children, but one study in infants after congenital heart surgery has shown splanchnic NIRS to be a valid and easy non-invasive monitoring tool to assess splanchnic oxygen demand and supply [12].

Table 2 summarizes the signs and symptoms used to assess feeding intolerance.

\section{Discussion}

\section{Decision-making at the bedside}

In essence, the complexity of critically ill children means that numerous factors can produce these, often very subjective, signs and symptoms. Healthcare staff often interpret these as feeding intolerance when they are not because of their insufficient specificity and sensitivity. Improved awareness by healthcare professionals of the limitations of these signs and symptoms is needed, as was called for in the first review paper of feeding intolerance in children in 2004 [46]. Feeding intolerance markers also need to be clearly distinguished from feeding intolerance predictors. The healthcare professional, firstly a nurse at the bedside, has to try to consider these factors and assess feeding tolerance, often seeking guidance from physicians, dieticians, and/or a unit protocol. However, identifying the causes of the sign/symptoms is a complex process. Often, a fear of the perceived risk and severity of feeding intolerance (such as vomiting and pulmonary aspiration) causes enteral nutrition cessation as a first action. However, identification and treatment of the cause of signs/symptoms would be better in the PICU setting, to avoid compromising nutrition goals. Most units utilize one or a combination of the
Table 2 Signs and symptoms used to define feeding tolerance and intolerance in critically ill infants and children

\begin{tabular}{|c|c|}
\hline Sign/symptom & Comment \\
\hline $\begin{array}{l}\text { Gastric residual volume (GRV) } \\
\text { Colour of gastric aspirate }\end{array}$ & $\begin{array}{l}\text { Most commonly used parameter, invalid marker of delayed gastric emptying, } \\
\text { definitions highly variable and no evidence to support "high" GRV and } \\
\text { prone to measurement error } \\
\text { Very subjective }\end{array}$ \\
\hline Vomiting (emesis) & May be induced by coughing, opiates and other drugs, withdrawal syndrome \\
\hline Diarrhea & $\begin{array}{l}\text { Definition problematic in infants and can be induced by infections, drugs, } \\
\text { bowel ischemia, withdrawal syndrome }\end{array}$ \\
\hline Stool output & May be useful if being fed enterally \\
\hline Abdominal distention & $\begin{array}{l}\text { Subjective unless girth measured accurately over time and may be induced by } \\
\text { other factors; no clear threshold }\end{array}$ \\
\hline Bowel sounds & No evidence relates to feed tolerance, are objective, but often poorly assessed \\
\hline Raised serum lactate & $\begin{array}{l}\text { Used commonly, different thresholds of tolerance used [Tume et al. 2017; } \\
\text { Valla et al. 2015] }\end{array}$ \\
\hline $\begin{array}{l}\text { Splanchnic NIRS (near-infrared } \\
\text { spectroscopy) }\end{array}$ & No research in critically ill children in relation to feed tolerance \\
\hline
\end{tabular}


simplistic markers listed above as a threshold for delaying, withholding, or initiating EN or additional therapies such as prokinetics. A more holistic approach should supplement local guidelines, but this requires better training to improve the knowledge of healthcare professionals.

\section{Actions to improve feed intolerance}

Common action taken to reduced feed intolerance in critically ill children include changing feed delivery method from intermittent bolus to continuous feeding or from gastric to transpyloric feeding, changing feed formulation (from polymeric to semi-elemental), or administering prokinetic agents. However, few of these have been comparatively studied. The two studies to examine continuous versus intermittent feeding $[7,10]$ found neither to be superior. Similarly, the two trials $[24,37]$ comparing gastric with transpyloric feeding found no difference, but the outcome used was ventilator-associated pneumonia, not feed tolerance. There are no studies on optimal feed formulation and feed tolerance/intolerance. Only one study on intravenous erythromycin [8] (used at a prokinetic dosage to facilitate transpyloric tube placement, not to improve feed tolerance) found the drug safe, but did not examine its impact on tolerance. Therefore, there is no evidence to suggest which, if any, interventions are effective in improving feed intolerance.

\section{A new pragmatic definition of feeding intolerance in critically ill children}

There is little or no development or progress in defining feeding intolerance made since a review paper on feeding intolerance in children was published in 2004 [46]. The international PICU community now urgently needs to agree a pragmatic consensus definition for feeding intolerance in the PICU, taking into account all the items described previously (feed related and non-feed related). Given the paucity of evidence around the components currently used to define feeding intolerance, this will not be evidence based, but would at least promote some consistency, both for research and for practice. This could then be used in future research, where feeding intolerance is used as an outcome.

\section{Conclusions}

Feeding intolerance (at least perceived intolerance) is common in the PICU. Decisions around enteral feeding involve a multidisciplinary team, and effective communication and collaboration between the bedside nurse, physician, and dietician is vital. Despite a paucity of evidence, GRV measurement continues to drive clinical bedside decisions about enteral feeding, readiness to feed, and feeding tolerance and advancement. Healthcare professionals need better education and guidance around the limitations of the signs and symptoms used to diagnose feeding intolerance, to enable them to better assess this complex phenomena. The generation of an agreed universal consensus definition would aid this.

Authors' Contributions LT conceived the idea for this paper and undertook the literature search and both authors worked on the review and manuscript.

\section{Compliance with ethical standards}

This paper complies with ethical standards.

Informed consent Informed consent is not applicable as this is a review.

Conflict of interest The authors declare that they have no conflict of interest.

Open Access This article is distributed under the terms of the Creative Commons Attribution 4.0 International License (http:// creativecommons.org/licenses/by/4.0/), which permits unrestricted use, distribution, and reproduction in any medium, provided you give appropriate credit to the original author(s) and the source, provide a link to the Creative Commons license, and indicate if changes were made.

\section{References}

1. Bartlett-Ellis R, Fuehne J (2015) Examination of accuracy in the assessment of gastric residual volume: a simulated, controlled study. JPEN J Parenter Enteral Nutr 39(4):434-440

2. Blaser R, Starkopf J, Kirsimagi U, Deane A (2014) Definition, prevalence, and outcome of feeding intolerance in intensive care: a systematic review and meta-analysis. Acta Anesthesiol Scand 58:914-922

3. Bown AM, Forbes M, Vitale V, Tirodker U, Zeller R (2017) Effects of a gastric feeding protocol on efficiency of enteral nutrition in critically ill infants and children. ICAN Infant Child Adolesc Nutr 4:175-180

4. Braegger C, Decsi T, Amil Dias J, Hartman C, Kolacek S, Koletzko B, Koletsko S, Mishatsch W, Marino L, Puntis J, Shamir R, Szajewska H, Turck D, van Goedoever J (2010) A practical approach to pediatric enteral nutrition: a comment by the ESPGHAN committee on nutrition. J Pediatr Gastroenterol 51: 110-122

5. Brown AM, Forbes M, Vitale V, Trodker U, Zeller R (2012) Effects of a gastric feeding protocol on efficiency of enteral nutrition in critically ill infants and children. ICAN Infant Child Adolesc Nutr 4:175-180

6. Elke G, Felbinger T, Heyland D (2015) Gastric residual volume in critically ill patients: a dead marker or still alive? Nutr Clin Pract 30(1):59-71

7. Fayazi S, Adineh M, Fard SZ, Payam H, Batvandy Z (2016) Comparing two methods of enteral nutrition in terms of their complications and the time needed to reach goal calorie in children hospitalized in ICU. Int J Pediatr 4:2119-2130

8. Gharpure V, Meert KL, Sarnaik AP (2001) Efficacy of erythromycin for postpyloric placement of feeding tubes in critically ill children: a randomized, double-blind, placebo controlled study. J Parenter Enter Nutr 25(3):16 
9. Hamilton S, McAleer D, Ariagno K, Barrett M, Stenquist N, Duggan C, Mehta N (2014) A stepwise enteral nutrition algorithm for critically ill children helps achieve nutrient delivery goals. Pediatric Crit Care Med 15:583-589

10. Horn D, Chaboyer W (2003) Gastric feeding in critically ill children: a randomized controlled trial. Am J Crit Care 12:461-468

11. Ista E, van Dijk M, Gamel C, Tibboel D, de Hoog M (2008) Withdrawal symptoms in critically ill children after long-term administration of sedatives and/or analgesics: a first evaluation. Crit Care Med 36:2427-2432. https://doi.org/10.1097/CCM. 0b013e318181600d

12. Kaufman J, Almodovar M, Zuk J, Friesen R (2008) Correlation of abdominal site near-infrared spectroscopy with gastric tonometry in infants following surgery for congenital heart disease. Pediatr Crit Care Med 9:62-68

13. Kuppinger D, Rittler P, Hartl W, Ruttinger D (2013) Use of gastric residual volume to guide enteral nutrition in critically ill patients: a brief systematic review of clinical studies. Nutrition 29:1075-1079

14. Lane M, Czyzewski D, Chumpitazi B, Shulman R (2011) Reliability and validity of a modified Bristol stool form scale for children. J Pediatr 159:437-441

15. Larsen B, Goonewardene L, Field C, Joffe A, van Aered J, Olstad D, Clandinin M (2013) Low energy intakes are associated with adverse outcomes in infants after open heart surgery. JPEN J Parenter Enteral Nutr 37:254-260

16. Leong A, Cartwright K, Guerra G, Joffe A, Mazurak V, Larsen B (2013) A Canadian survey of perceived barriers to initiation and continuation of enteral feeding in PICUs. Pediatr Crit Care Med 15: e45-e55. https://doi.org/10.1097/PCC.0000000000000016

17. Lopez J, Botran M, Garcia A, Gonzalez R, Solana M, Urbano J, Fernandez S, Sanchez C, Lopez-Herce J (2015) Constipation in the critically ill child: frequency and related factors. J Pediatr 167:857-861

18. Lopez-Herce J (2009) Gastrointestinal complications in critically ill patients: what differs between adults and children? Curr Opin Clin Nutr Metab Care 12:180-185

19. Lyons K, Brilli R, Wieman R, Jacobs B (2002) Continuation of transpyloric feeding during weaning of mechanical ventilation and tracheal extubation in children: a randomized controlled trial. JPEN J Parenter Enteral Nutr 26:209-213

20. Martinez E, Douglas K, Nurko S, Mehta N (2015) Gastric dysmotility in critically ill children: pathophysiology, diagnosis and management. Pediatr Crit Care Med 16:828-836. https://doi. org/10.1097/PCC.0000000000000493

21. Martinez E, Pereira L, Gura K, Stenquist N, Ariagno K, Nurko S, Mehta N (2017) Gastric emptying in critically ill children. JPEN J Parenter Enteral Nutr 41:1100-1109. https://doi.org/10.1177/ 0148607116686330

22. Mayer A, Durward A, Turner C, Skellet S, Dalton N, Tibby S, Murdoch I (2002) Amylin is associated with delayed gastric emptying in critically ill children. Intensive Care Med 28:336-340

23. Medicine.Net online medical dictionary. https://www.medicinenet. $\mathrm{com} / \mathrm{script} / \mathrm{main} /$ art.asp?articlekey=11527 accessed 3/11/17

24. Meert K, Daphtary K, Metheny N (2004) Gastric vs small bowel feeding in critically ill children receiving mechanical ventilation: a randomized trial. Chest 126:872-878

25. Mehta N, McAleer D, Hamilton S, Naples E, Leavitt K, Mitchell P, Duggan C (2010) Challenges to optimal enteral nutrition in a multidisciplinary pediatric intensive care unit. JPEN J Parenter Enteral Nutr 34:38-45

26. Mehta N, Skilman H, Irving S, Coss-bu J, Vermilyea S, Farrington E, McKeever L, Hall A, Goday P, Braunschweig C (2017) Guidelines for the provision and assessment of nutrition support therapy in the pediatric critically ill patient: Society of Critical Care Medicine and American Society for Parenteral and Enteral Nutrition. JPEN J Parenter Enteral Nutr 18:675-715
27. Ozen N, Tosun N, Yamanel L, Altintas N, Kilciler G, Ozen V (2016) Evaluation of the effect on patient parameters of not monitoring gastric residual volume in intensive care patients on a mechanical ventilator receiving enteral nutrition: a randomized clinical trial. J Crit Care 33:137-144

28. Panchal A, Manzi J, Conolly S et al (2014) Safety of enteral feedings in critically ill children receiving vasoactive agents. JPEN J Parenter Enteral Nutr 40(2):236-241

29. PICUTrials.Net http://picutrials.net/ McMaster University Canada, Duffet M. Accessed 1 May 2018,

30. Reignier J, Mercier E, Le Gouge A, Boulain T, Desachy A, Bellec F, Clavel M, Frat JP, Plantefeve G, Quenot JP, Lascarrou JB (2013) Effect of not monitoring residual gastric volume on risk of ventilator-associated pneumonia in adults receiving mechanical ventilation and early enteral feeding. JAMA 2013:309(3)

31. Reismann M, von Kampen M, Laupicler B (2007) Fast track surgery in infants and children. J Pediatr Surg 42:243-248

32. Reismann M, Dingemann J, Wolters M, Suempelmann R, Schmidt A, Ure B (2009) Fast-track concepts in routine pediatric surgery: a prospective study in 436 infants and children. Langenbeck's Arch Surg 394:529-533. https://doi.org/10.1007/s00423-008-0440-1

33. Sanchez C, Lopez-Herce J, Carillo A, Mencia S, Vigil D (2007) Early transpyloric enteral nutrition in critically ill children. Nutrition 23:16-22

34. Sanchez C, Lopez-Herce J, Carillo A, Bustinza A, Sancho L, Vigil D (2007) Transpyloric enteral feeding in the postoperative of cardiac surgery in children. J Pediatr Surg 41:1096-1102

35. Simackachorn N, Bibiloni R, Yimyaem P, Tongpenyai Y, Yarayithaya W (2011) Tolerance, safety, and effect on the faecal microbiota of an enteral formula supplemented with pre- and probiotics in critically ill children. J Pediatr Gastroenterol Nutr 53:174-181

36. Smalley N, Vangaveti V (2014) Assessing the bowel function of critically ill children: a pilot study. Crit Care Resusc 16:202-205

37. Somnez-Duzkaya D, Yildiz S (2016) The effect of two different feeding methods on preventing ventilator associated pneumonia in paediatric intensive care units. Aust Crit Care 29:139-145

38. Tarling MM, Toner CC, Withington PS, Whelpton B, Goldhill D (1997) A model of gastric emptying using paracetamol absorption in intensive care patients. Intensive Care Med 23:256-260

39. Thabut F, Bougmeza I, Chehab M, Bafiqah A, Almohaimeed M, Malbrain M (2015) Incidence, risk factors, and prognosis of intraabdominal hypertension in critically ill children: a prospective epidemiological study. J Intensive Care Med:1-6

40. Tume L, Carter B, Latten L (2012) A UK and Irish survey of enteral nutrition practices in paediatric intensive care units. Br J Nutr 109: 1304-1322. https://doi.org/10.1017/S0007114512003042

41. Tume LN, Latten L, Kenworthy L (2017) Paediatric intensive care nurses' decision-making around gastric residual volume measurement. Nurs Crit Care 22:293-297. https://doi.org/10.1111/nicc. 12304

42. Tume LN, Bickerstaff A, Latten L, Davies S, Lefèvre M, Nicolas G, Valla FV (2017) Routine gastric residual volume measurement and energy target achievement in the PICU: a comparison study. Eur J Peds 176:1637-1644. https://doi.org/10.1007/s00431-017-3015-8

43. Tume LN, Balmaks R, da Cruz E, Latten L, Verbruggen S, Valla FV, on behalf of the members of the European Society of Pediatric and Neonatal Intensive Care Congenital Cardiac and \& Mechanical support section and the Metabolism, Endocrine and Nutrition section and the Nurse Science sections (2018) European Practices in enteral feeding in infants with congenital heart disease: an ESPNIC survey. Pediatr Crit Care Med 19:137-144. https://doi.org/10.1097/ PCC.0000000000001412

44. Valla F, Gaillard-Le Roux B, Ford-Chessel C, De Monte M, Tume LN, Letois F, Choueiri E, Rooze S, Moullet C, Jacquot A (2016) A nursing survey on nutritional care practices in French-speaking 
pediatric intensive care units: NutriRea-Ped 2014. J Pediatr Gastroenterol Nutr 62(1):174-179

45. Van Waardenburg D, de Betue C, van Goudoever J, Zimmerman L, Joosten K (2009) Critically ill infants benefit from early administration of protein and energy-enriched formula: a randomized controlled trial. Clin Nutr ESPEN 28:249-255

46. Weckworth J (2004) Monitoring enteral nutrition support tolerance in infants and children. Nutr Clin Pract 19:496-503

47. Wiesen P, Van Gossum A, Preiser JC (2006) Diarrhoea in the critically ill. Curr Opin Crit Care 12:149-154. https://doi.org/10.1097/ 01.ccx.0000216583.64804.46
48. Willis T, Thureen P, Kaufman J, Wymore E, Skillman H, da Cruz E (2008) Enteral feeding in prostaglandin-dependent neonates: is it a safe practice? J Pediatr 153:867-869

49. Wong J, Han W, Sultana R et al (2016) Nutrition delivery affects outcomes in pediatric acute respiratory distress syndrome. JPEN J Parenter Enteral Nutr 41:1007-1013. https://doi.org/10.1177/ 0148607116637937

50. Yoshimuru S, Miyazu M, Yoshizawa S, So M, Kusama N, Sobue K, $\mathrm{He} \mathrm{H}$ (2015) Efficacy of an enteral feeding protocol for providing nutritional support after paediatric cardiac surgery. Anaesth Intensive Care 43:587-593 